\title{
Caracterización electroforética de las proteínas del corion normal y del corion duro de Salmo salar ${ }^{\#}$
}

\author{
Electrophoretic characterization for both normal and hard chorion proteins \\ of Salmo salar \\ R Jaramillo*, O Goicoechea, O Garrido, E Molinari \\ Instituto de Ciencias Marinas y Limnológicas, Facultad de Ciencias, Universidad Austral de Chile, Valdivia, Chile.
}

\begin{abstract}
SUMMARY
The chorion is an egg envelope that allows the early development of teleostean fishes. After reaching the alevin stage, hatching enzymes are secreted in order to digest the chorion and release the alevin. Massive mortality events have occurred in a number of salmon farms as a consequence of hatching problems, with alevins being unable to degrade the chorion. A previous study on the chorion structure of Salmo salar has shown that protein fibers forming the inner layer of non-degraded chorion are thicker than those observed in normal chorion, suggesting that polypeptides forming the choriogenin could exhibit an altered structure. It would be interesting to make a biochemical comparison between polypeptides forming protein fibers of the inner layer of normal and hard chorion in order to establish differences in the electrophoretic pattern of Salmo salar ova. According to our results, fibers forming the inner layer of normal chorion are thinner than those building the hard chorion. The electrophoretic pattern for normal chorion is described as four bands of molecular weight $107 \mathrm{kDa}, 92 \mathrm{kDa}, 38 \mathrm{kDa}$, and $31 \mathrm{kDa}$ in contrast to the $179 \mathrm{Kda}, 157 \mathrm{Kda}, 55 \mathrm{Kda}$ and $54 \mathrm{Kda}$ for non-hatched chorion. Consequently, protein fibers with higher molecular weight turned into thicker fibers with a different three dimensional structure, but also with different glycosylic radicals compared to normal fibers. These features make the inner layer of hard chorion different to normal chorion since it is very difficult for the hatching enzyme to dissolve it, leading the alevin to fail in the hatching process.
\end{abstract}

Palabras clave: Salmo salar, reproducción, ultraestructura, corion.

Key words: Salmo salar, reproduction, ultrastructure, chorion.

\section{INTRODUCCIÓN}

Las ovas de peces teleósteos presentan una envoltura primaria externa denominada envoltura vitelina o corion (Celius y Walther 1998). Esta envoltura se organiza a partir de una proteína compleja llamada coriogenina (Darie y col 2005) que es sintetizada durante la ovogénesis en el hígado de la hembra de peces teleósteos. La coriogenina está formada por tres o más subunidades (Iuchi y col 1991, Celius y Walther 1998), las cuales son sintetizadas por influencia del $17 \beta$ estradiol y transportadas a través del torrente sanguíneo hasta llegar al ovocito en donde se ensamblan para constituir la cubierta protectora denominada corion (Sugiyama y col 1999).

Si bien es cierto que el corion es una membrana blanda mientras se encuentra en el ovario, una vez ocurrida la ovulación se inicia un proceso continuo de endurecimiento que termina poco después de la fecundación cuando se produce un aumento en la concentración de iones $\mathrm{Ca}^{2+}$ en la zona periférica del ovocito, con lo cual los gránulos corticales liberan un tipo de polisacárido ácido glicosilado

\footnotetext{
Aceptado: 29.09.2011.

\# Proyecto DID-UACH S-2009-50

* Casilla 567, Valdivia, Chile; jjaramil@uach.cl
}

demasiado grande para atravesar el corion, razón por la cual permanece confinado entre el corion y la membrana plasmática del ovocito contribuyendo a la formación del espacio perivitelino (McMillan 2007). El polisacárido liberado por los gránulos corticales incrementa la osmolaridad del fluido presente en el espacio perivitelino, produciéndose una movilización de agua y electrolitos hacia el interior del huevo fecundado incrementando la presión osmótica del espacio perivitelino. El aumento de la presión osmótica a su vez obliga a que las fibras elásticas del corion se expandan y pierdan elasticidad, con lo cual el corion se endurece (McMillan 2007).

El corion posee una perforación denominada micrópilo que facilita el acceso del espermatozoide hasta el ovocito para que ocurra la fecundación. Una vez ocurrida la fecundación, y formado el espacio perivitelino, el endurecimiento del corion permite establecer una barrera protectora del embrión en el medio ambiente. El desarrollo de los embriones de teleósteos ocurre, entonces, al amparo de la acción protectora del corion; sin embargo, una vez alcanzado el estado de ova con ojo se inicia la producción de la enzima de eclosión, encargada de liberar el alevín desde su envoltura protectora (Yamagami 1981). La enzima de eclosión, llamada coriolisina (endoproteasa proteolítica), inicia el proceso de degradación de la pared interna del corion, con lo cual se produce el adelgazamiento 
y debilitamiento progresivo de esta envoltura, facilitando con ello la ruptura y subsecuente salida de los alevines con saco desde el interior del corion, fenómeno conocido como eclosión (Yamagami 1981).

En condiciones normales, el endurecimiento del corion ocurrido durante la fecundación permite que el embrión se desarrolle de manera adecuada y posteriormente que las enzimas de degradación faciliten la eclosión del alevín de salmón. Sin embargo, en algunas pisciculturas dedicadas a la producción de alevines de salmónidos se han observado fracasos reproductivos importantes como resultado de que un gran porcentaje de ovas con ojo de algunas cohortes no logran romper el corion (no eclosionan), produciéndose con ello la muerte del alevín. En el mejor de los casos en los cuales se ha observado este problema, un porcentaje menor de alevines logra romper el corion de manera parcial, por lo que una parte del cuerpo del embrión o parte de su saco vitelino eclosiona, quedando el resto del embrión o del saco atrapado al interior de la cavidad coriónica, lo que conduce a la muerte del alevín.

En estos casos aparentemente el corion se ha transformado en una barrera difícil de romper o de degradar por parte de las enzimas de eclosión, refiriéndose comúnmente como condición de "corion duro". Se desconoce hasta ahora la razón por la cual el corion no es digerido o digerido sólo de manera parcial por las enzimas de eclosión.

El corion duro ha sido observado principalmente en ovas de Salmo salar y Oncorhynchus kisutch; sin embargo, existe información de que este fenómeno también ocurre en otras especies cultivadas en el sur de Chile, tales como Salmo trutta y Oncorhynchus mykiss.

Una primera aproximación para entender este fenómeno son los resultados reportados por Jaramillo y col 2009, quienes realizaron un análisis comparativo entre la estructura del corion normal y el corion duro de Salmo salar, estableciendo que las fibras proteicas que forman el estrato interno del corion duro son más gruesas que las presentes en el corion normal, lo que trae como consecuencia adicional la ausencia de poros en el estrato interno del corion duro. Estos resultados condujeron a pensar que una o más de las subunidades constituyentes de la coriogenina podrían estar alteradas en su estructura y por lo tanto formarían un corion más grueso y difícil de digerir.

La literatura disponible respecto de la estructura normal del corion de teleósteos indica que en el caso de Oncorhynchus mykiss la coriogenina está constituida por cuatro subunidades glicoproteicas de $129 \mathrm{KDa}, 62 \mathrm{KDa}$, 54 KDa y 47 KDa (Brivio y col 1991). Todas ellas poseen, entre otras características, una señal peptídica N-terminal y una región rica en prolina-glutamina, además de presentar un alto grado de similitud de secuencias génicas entre ellas y también con las proteínas que forman la envoltura de los huevos de mamíferos (Lyons y col 1993, Murata y col 1997).

Si bien es cierto que esta información describe con mucha precisión las propiedades químicas de las proteínas que forman el corion normal, no es suficiente para proponer una explicación de lo que pueda ocurrir con dichas propiedades en el caso de presentarse el fenómeno de corion duro. Una forma de aproximarse a dilucidar el origen del corion duro es caracterizar el patrón electroforético de las proteínas que participan en la formación del corion alterado de manera de poder compararlas con las proteínas que forman el corion normal de ovas de Salmo salar, para luego y a partir de dichos resultados proponer una respuesta funcional más que morfológica acerca de este problema.

\section{MATERIAL Y MÉTODOS}

\section{RECOLECCIÓN DE MUESTRAS}

A partir de un pool de ovas fecundadas de Salmo salar que mostraron desarrollo embrionario, provenientes de una piscicultura situada en la Región de Los Lagos, se tomaron muestras del corion de alevines que lograron eclosionar de manera normal; paralelamente se tomaron muestras de corion proveniente de alevines que lograron degradar parcialmente el corion y no lograron eclosionar. Los trozos de corion así obtenidos fueron mantenidos en agua a $4{ }^{\circ} \mathrm{C}$ para posteriormente ser trasladados, en una caja refrigerada, hasta el laboratorio de microscopía del Instituto de Embriología de la Universidad Austral de Chile en Valdivia.

Con la finalidad de establecer con precisión el carácter de desarrollo normal y anormal del corion de las ovas muestreadas se realizó un análisis ultraestructural de la morfología del corion a la microscopía electrónica de barrido (MEB).

\section{ANÁLISIS A LA MICROSCOPÍA ELECTRÓNICA DE BARRIDO}

Un total de 45 ovas fue utilizado para el estudio de la ultraestructura, para lo cual se extrajeron trozos de corion de $3 \mathrm{~mm}$ de espesor mediante el uso de pinzas quirúrgicas. Los fragmentos extraídos fueron inmediatamente fijados con glutaraldehído al 2,5\% en buffer fosfato $\mathrm{pH}$ 7,2 para luego ser almacenados a $4{ }^{\circ} \mathrm{C}$. El segmento de corion restante fue destinado al análisis electroforético, para lo cual se les individualizó mediante un número y se les mantuvo a $4{ }^{\circ} \mathrm{C}$ en tubo Eppendorf hasta el momento de iniciar el análisis electroforético.

Una vez fijadas, las muestras de corion se lavaron en buffer fosfato de sodio, $\mathrm{pH}$ 7,2-7,4 (0,2 M) y postfijadas en tetróxido de osmio $\left(\mathrm{O}_{\mathrm{s}} \mathrm{O}_{4}\right)$ al $1 \%$ en el mismo buffer durante $2 \mathrm{~h}$ a $4{ }^{\circ} \mathrm{C}$. Más tarde se extrajo el excedente del fijador mediante lavados con buffer fosfato de sodio, $\mathrm{pH}$ 7,2-7,4 (0,2 M). Finalmente se procedió a deshidratar las muestras en concentraciones crecientes de alcohol y acetona, seguido de secado al punto crítico del $\mathrm{CO}_{2}$ (Hitachi HCP-2 critical point dryer). Las muestras fueron montadas en un portaespécimen, recubiertas con una película de oro de aproximadamente 10 a $15 \mathrm{~nm}$ de espesor (Ion coater 
IB-2) y observadas en un microscopio electrónico de barrido LEO-420. De acuerdo a las características ultraestructurales observadas, las muestras de corion fueron clasificadas en i) normal (ovas eclosionadas) o ii) corion duro (ovas no eclosionadas) de acuerdo al patrón de distribución de las fibras (fibras ordenadas o distribuidas al azar).

\section{ANÁLISIS DE IMÁGENES}

Una vez establecida la condición de corion normal o corion duro y con la finalidad de validar los criterios morfológicos descritos, se procedió a hacer mediciones del grosor de las fibras que forman el estrato interno del corion y el número de poros por cada $100 \mu \mathrm{m}^{2}$. Para ello se procedió a analizar las fotografías de corion, obtenidas a la MEB, mediante el software Sigmascan-pro5 (SPSS Inc.).

\section{SOLUBILIZACIÓN DEL CORION}

Para iniciar el estudio electroforético, se procedió a reunir en un tubo de Eppendorf el total de muestras previamente refrigeradas y correspondientes a 30 unidades de corion normal, mientras que en otro tubo se dispusieron las 15 restantes que presentaron la condición de corion duro.

Para iniciar el proceso de extracción de las proteínas se procedió a cortar el corion, en trozos de no más de $5 \mathrm{~mm}^{2}$, mediante el uso de un bisturí, más tarde los trozos fueron macerados en un mortero para finalmente solubilizar las proteínas en urea $8 \mathrm{M}$ (Sigma Chemical) en tampón fosfato de sodio $0,1 \mathrm{M}, \mathrm{pH}$ 6,8 e incubadas durante $15 \mathrm{~min}$ a $100{ }^{\circ} \mathrm{C}$. El total de proteínas obtenidas como producto de la solubilización fue tratado con SDS 20\%, $\beta$-mercaptoetanol y tampón de muestra preparado con glicerol $87 \%$, azul de bromofenol y buffer Tris-HCL 0,5 M, pH 6,8.

Se confeccionó una curva de calibración utilizando como patrón de medida albúmina sérica bovina en una concentración $2 \mathrm{mg} / \mathrm{ml}$ (Sigma Chemical). La determinación de la concentración de las proteínas obtenidas se realizó mediante la medición de la absorbancia a una longitud de onda de $595 \mathrm{~nm}$ (Spectronic 21D).

\section{SEPARACIÓN ELECTROFORÉTICA DE PROTEÍNAS}

La separación de proteínas se realizó en geles de poliacrilamida en condiciones denaturantes (SDS-PAGE) de acuerdo a lo descrito por Laemmli (1970), tanto el gel separador y espaciador fueron preparados a partir de una solución de acrilamida-bisacrilamida 29\%:1\%. La concentración para el gel separador fue al 10\%, junto con Tris-HCL 1,5 M, $\mathrm{pH} 8,8$, SDS, persulfato de amonio (BRL Life Technologies) al $1 \%$ y $16 \mu \mathrm{m} \mathrm{N,N,N'N'-tetramethylethylenediamina}$ (TEMED), mientras que la polimerización del gel espaciador se realizó al $4 \%$, conteniendo Tris-HCL $0,5 \mathrm{M}$, pH 6,8, SDS, persulfato de amonio al $1 \%$ y $5 \mu \mathrm{m}$ de TEMED (Sigma Chemical).
Para conocer el peso molecular aparente de las proteínas del corion se corrió en un carril del gel un marcador de peso molecular de proteínas, el cual contenía una serie de proteínas de peso molecular conocido con patrones de $250,130,95,72,55,36$ y $28 \mathrm{kDa}$ respectivamente, mientras que en los carriles restantes se ubicaron muestras de corion normal y corion duro. Para la corrida del gel, se utilizó un equipo de electroforesis vertical BIO RAD® (modelo Mini-PROTEAN) y una fuente de poder BIO RAD® (modelo PowerPac 200). La corrida se desarrolló a temperatura ambiente durante 90 minutos con un voltaje de $100 \mathrm{~V}$, y usando Tris $0,1 \mathrm{M}$, glicina $0,768 \mathrm{M}$ y SDS 0,4\% como tampón de corrida.

Terminada la electroforesis, el gel fue sometido a una solución de fijado compuesta de isopropanol + ácido acético en proporciones de 25\%:10\%) durante una hora, teñido con azul solución brillante de Coomassie R-250 $0,3 \%$ y metanol $50 \%$ por una hora, para finalizar con la decoloración mediante lavados sucesivos en una solución de metanol al $25 \%$ y ácido acético al $7 \%$ por doce horas. Todas las incubaciones se realizaron con agitación y a temperatura ambiente.

\section{RESULTADOS}

\section{ULTRAESTRUCTURA DEL CORION}

Los resultados obtenidos a partir de los análisis de microscopía electrónica de barrido del corion de ovas eclosionadas (con desarrollo normal) y con eclosión defectuosa o alterada (corion duro) de Salmo salar, permitieron confirmar resultados presentados en un trabajo previo (Jaramillo y col 2009) confirmando que el corion está compuesto por tres estratos o capas diferentes: el estrato interno o capa externa; el estrato medio o esponjoso y el estrato interno.

La principal diferencia entre un corion normal y un corion duro está representada por la estructura del estrato interno del corion (figuras 1 y 2). En el caso del corion normal, las fibras se distribuyen de manera ordenada y equidistante de manera que el estrato toma la apariencia de una red. En el caso del corion anormal las fibras se distribuyen al azar, constituyendo un estrato irregular y totalmente asimétrico.

Todos estos indicadores morfológicos fueron utilizados para clasificar las muestras como corion normal o corion duro para luego hacer el análisis electroforético de cada una.

Puesto que el corion corresponde a una envoltura primaria formada por una compleja red de fibras proteicas muy entrelazadas, la solubilidad de la estructura es muy baja y las proteínas difíciles de disociar. El tratamiento de trozos de corion con altas concentraciones de urea $(8 \mathrm{M})$ junto con un breve tratamiento térmico a $100{ }^{\circ} \mathrm{C}$ permitieron obtener un extracto total soluble de proteínas para el caso de corion normal y anormal, 
los que posteriormente fueron utilizados para el análisis electroforético.

\section{ANÁLISIS DE IMÁGENES}

Los resultados del análisis de las fibras que forman el estrato interno del corion duro o anormal permitieron establecer que éstas midieron en promedio $0,27 \mu \mathrm{m}$ de ancho ( $\pm 0,102$ STD), mientras que las fibras que forman el mismo estrato en el caso de corion con desarrollo normal alcanzaron en promedio los $0,23 \mu \mathrm{m} \pm 0,087 \mathrm{STD}$ (cuadro 1).

Otro aspecto importante de la ultraestructura es que la distribución de las fibras en el estrato interno del corion con desarrollo normal tiene una formación regular que permite la formación de poros (figura 1). El número promedio de poros para el corion con desarrollo normal fue de 69 por unidad de superficie (equivalentes $100 \mu^{2}$ ). En el caso de las ovas con desarrollo anormal la distribución de las fibras es al azar (figura 2), por lo cual no hay tendencia a la formación de poros y consecuente con ello ocurre una disminución en su número. En este caso el promedio de poros por unidad de superficie fue de 42 (cuadro 1).

\section{ANÁLISIS ELECTROFORÉTICO DE FIBRAS DEL CORION}

Los resultados obtenidos a partir de tres corridas electroforéticas, SDS-PAGE, de un extracto total de proteínas de corion normal, mostraron la existencia de un patrón común de migración, el cual correspondió a cuatro bandas claramente teñidas con Azul de Coomasie correspondientes a polipéptidos de naturaleza glicoproteína de peso molecular $107 \mathrm{kDa}, 92 \mathrm{kDa}, 38 \mathrm{kDa}$ y $31 \mathrm{kDa}$ respectivamente (figura 3 carriles A y B).

En lo que respecta al corion de ovas anormales, el número de bandas presentes en los carriles $\mathrm{C}$ y $\mathrm{D}$ (figura 3 ) son similares al número de bandas registradas en el patrón electroforético de corion normal; sin embargo, se observan diferencias con respecto al tamaño de los polipéptidos, ya que en este caso (ovas anormales) las bandas se ubicaron en los valores de $179 \mathrm{kDa}, 157 \mathrm{kDa}, 64 \mathrm{kDa}$ y $55 \mathrm{kDa}$.

Las bandas observadas para el caso de ovas anormales se situaron en valores de peso molecular superiores a los registrados para el corion de ovas normales (figura 3). Estos valores son significativamente diferentes (cuadro 2) puesto que los pesos de las bandas del corion anormal (179 Kda, $157 \mathrm{Kda}, 55 \mathrm{Kda}$ y $54 \mathrm{Kda}$ ) tienen una equivalencia de entre 1,4 y 1,7 veces el peso de las respectivas bandas provenientes del corion de ovas con desarrollo normal (107 Kda, 62 Kda, 38 Kda y $31 \mathrm{Kda}$ ).

\section{DISCUSIÓN}

Los resultados del análisis electroforético para ovas con desarrollo normal de Salmo salar difieren en el número de bandas y también en peso molecular con respecto a resultados descritos para la misma especie por Celius y

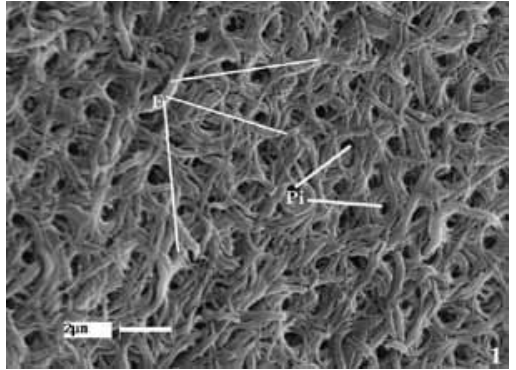

Figura 1. MEB del estrato interno de ova normal de Salmo salar. $(\mathrm{F}=$ fibras; $\mathrm{Pi}=$ poro interno proteicas $)$.

SEM view of chorion's inner stratum for a hatched ova of Salmo salar $(\mathrm{F}=$ protein fibers; $\mathrm{Pi}=$ inner pore $)$.

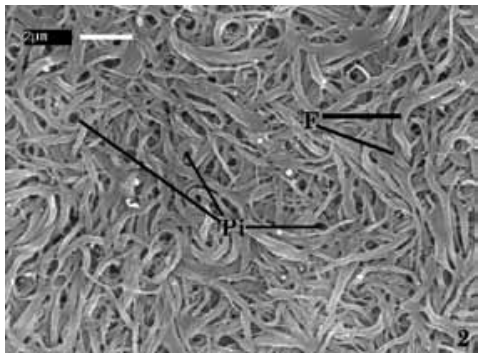

Figura 2. MEB del estrato interno de ova anormal de Salmo salar. $(\mathrm{F}=$ fibras proteicas; $\mathrm{Pi}=$ poro interno $)$.

SEM view of chorion's inner stratum for a not-hatched ova of $\operatorname{Salmo~} \operatorname{salar}(\mathrm{F}=$ protein fibers; $\mathrm{Pi}=$ inner pore $)$.

Cuadro 1. Análisis comparativo del grosor de fibras proteicas y número de poros presentes en el corion normal y el corion duro. Comparative analysis between normal and hard chorion for protein fibers thickness and pore number.

\begin{tabular}{lcc}
\hline \multicolumn{1}{c}{ Parámetros estimados } & \multicolumn{2}{c}{ Salmo salar } \\
\hline normal & $\begin{array}{c}\text { Corion } \\
\text { anormal }\end{array}$ \\
\hline Grosor promedio de fibras $(\mu \mathrm{m})$ & 0,23 & 0,27 \\
Desviación estandar $( \pm)$ & 0,087 & 0,102 \\
$\mathrm{~N}^{\mathbf{o}}$ de poros & 69 & 42 \\
\hline
\end{tabular}

Walther (1998). Dichos autores indican que son sólo tres las bandas observadas y cuyos pesos moleculares corresponderían a: $66 \mathrm{Kda}, 61 \mathrm{Kda}$ y $55 \mathrm{Kda}$ respectivamente. Esta diferencia en el número de bandas puede ser explicada debido a que el corion estudiado por Celius y Walther (1998) corresponde al de ovas no activadas (ni fecundadas) y que no han completado el proceso de endurecimiento normal del corion.

Durante el endurecimiento normal del corion se produce la polimerización de las subunidades proteicas de la coriogenina por acción de la transglutaminasa (Iuchi y col 1991). Estudios realizados en Oncorhynchus mykiss indican que posterior al proceso de activación de las ovas, las distintas subunidades de la coriogenina pueden 


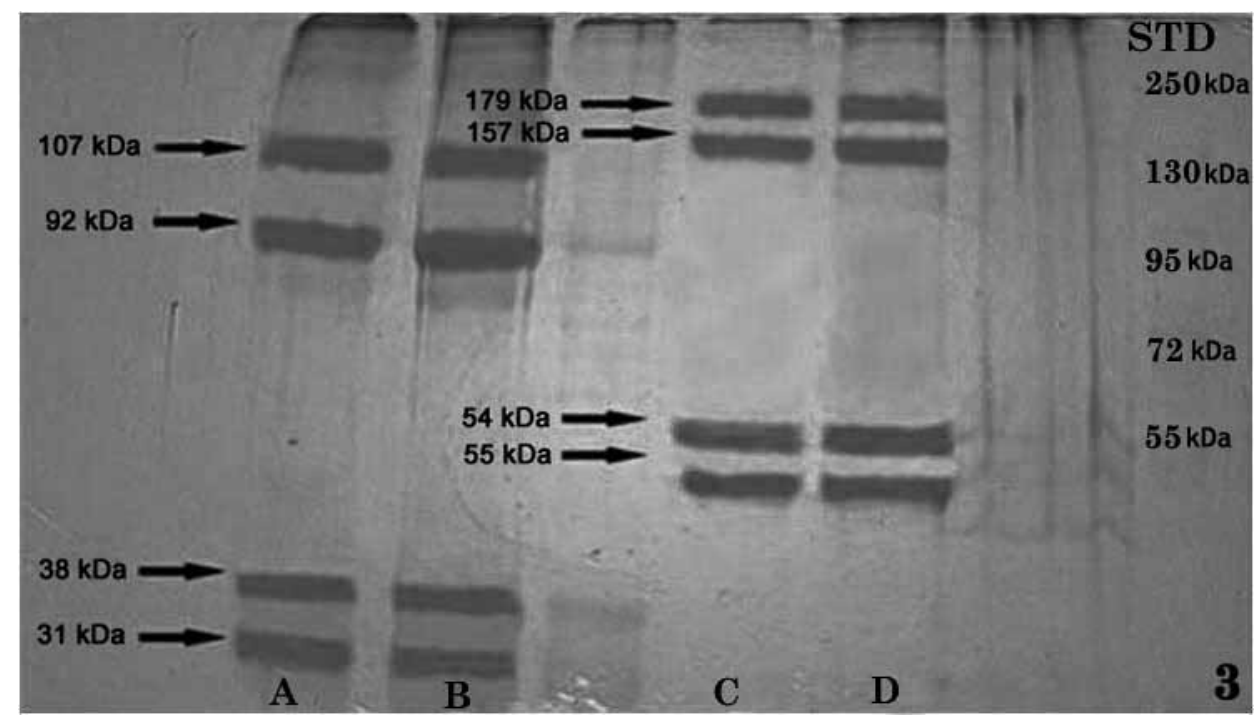

Figura 3. Fotografía de un gel SDS-PAGE mostrando la separación de cuatro bandas producidas para extractos de proteínas de corion normal (A y B) y de corion anormal (C y D) de Salmo salar. El carril STD corresponde al estándar de peso molecular. Las flechas indican la posición de las bandas y el peso de cada una de ellas.

SDS-PAGE showing four different proteins being separated from a normal chorion concentrate (lines A and B) and not-hatched ova concentrate (lines C and D). Lane STD represents molecular weight standards of known sizes. Arrows showing position and weight for each separate protein.

Cuadro 2. Análisis comparativo del peso de las subunidades de la coriogenina normal y de corion duro.

Comparative analysis of molecular weight of coriogenin sub-units for normal and hard chorion.

\begin{tabular}{lccc}
\hline \multirow{2}{*}{ Subunidad } & \multicolumn{3}{c}{ Salmo salar } \\
\cline { 2 - 4 } & $\begin{array}{c}\text { Corion } \\
\text { normal } \\
\text { (Kda) }\end{array}$ & $\begin{array}{c}\text { Corion } \\
\text { anormal } \\
\text { (Kda) }\end{array}$ & $\begin{array}{c}\text { relación } \\
\text { anormal/ } \\
\text { normal }\end{array}$ \\
\hline 1 & 107 & 179 & 1,7 \\
2 & 92 & 157 & 1,7 \\
3 & 38 & 55 & 1,4 \\
4 & 31 & 54 & 1,7 \\
\hline
\end{tabular}

asociarse a diferentes componentes glucosídicos para formar glicoproteínas distintas, las cuales incluso pueden ser de mayor peso molecular que el registrado antes de la activación del huevo (Iuchi y col 1991); dicho proceso de polimerización podría entonces explicar la aparición de bandas adicionales y con características estructurales diferentes a las observadas previo a la activación y que podrían corresponder a polipéptidos existentes antes de la fecundación.

Estudios preliminares realizados con lectinas (datos no publicados) nos han permitido establecer que concanavalina A (ConA) reacciona uniéndose específicamente a restos de D-glucosa y D-manosa presentes principalmente en el estrato externo e interno del corion normal, mientras que en el caso del corion anormal la reacción ocurre principalmente en el estrato externo. La lectina LFA (Limax flavus), que reconoce el ácido siálico, produjo reacción en los tres estratos tanto del corion normal como del anormal. La lectina WGA (Wheat germ agglutinin) que tiene preferencia por la $\mathrm{N}$ acetil $\mathrm{D}$ Glucosamina fue reconocida sólo en el estrato externo del corion normal mientras que en el corion anormal su detección se realizó en los tres estratos. Estos resultados sugieren que la coriogenina de Salmo salar corresponde a una serie de polipéptidos glicosilados que pueden presentar, entre otros, radicales glucosa, manosa, acido siálico y glucosamina como parte de sus componentes. La reacción diferencial de las lectinas ConA y WGA nos sugiere que glucosa, manosa y glucosamina se asocian de manera diferente a los polipéptidos que forman la coriogenina, pudiendo determinar con ello la formación de polipéptidos de peso molecular distinto dependiendo del tipo y de la cantidad de radicales glicosídicos asociados al polipéptido. De esta manera, polipéptidos de diferente peso molecular se pueden asociar a la condición de normal o anormal del corion determinando con ello la capacidad de eclosión (o no eclosión) del alevín.

Nuestros resultados son coincidentes con la descripción hecha para la coriogenina de Oncorhynchus mykiss, la cual está compuesta de cuatro subunidades de diferente peso molecular (Iuchi y col 1991); sin embargo, tres de las subunidades de Salmo salar (107 Kda, 38 Kda y 31 Kda) son más livianas que sus equivalentes reportadas por Brivio y col (1991), para O. mykiss (129 Kda, $54 \mathrm{Kda}$ y $47 \mathrm{Kda}$ respectivamente), sólo la subunidad de peso $92 \mathrm{Kda}$ de 
$S$. salar supera a la de $62 \mathrm{Kda}$ de $O$. mykiss (Brivio y col 1991). Estas diferencias en peso son sólo explicables en función de las diferencias especie específicas, ya que la coriogenina exhibe una secuencia de aminoácidos muy similar entre las diferentes especies de teleósteos (Darie y col 2005).

En general, las subunidades polipeptídicas que forman parte del corion tienen una secuencia promedio de 260 aminoácidos, además de poseer un extremo peptídico $\mathrm{N}$ - terminal y una región rica en prolina-glutamina; siendo estas últimas regiones las que otorgan características propias a cada banda y a su vez hacen las diferencias entre las bandas; además son las responsables de la polimerización de la coriogenina en forma de fibras alargadas que caracteriza al corion de los teleósteos (Iuchi y col 1991).

Jaramillo y col (2009) indican que las fibras que forman el corion duro son más gruesas que las fibras del corion normal, así como también que las fibras proteicas del corion duro tienen una disposición diferente a las fibras que forman el corion normal. Los resultados aquí presentados contribuyen a sustentar dichas afirmaciones. Adicionalmente, en este trabajo se aportan antecedentes respecto a los pesos moleculares de las fibras y al número de poros presentes en el estrato interno del corion de Salmo salar. En el caso de las fibras del corion anormal los pesos fueron de $179 \mathrm{Kda}, 157 \mathrm{Kda}, 55 \mathrm{Kda}$ y $54 \mathrm{Kda}$, mientras que las fibras de corion normal exhibieron pesos de $107 \mathrm{Kda}, 92 \mathrm{Kda}, 38 \mathrm{Kda}$ y $31 \mathrm{Kda}$. Estos resultados muestran que en promedio, el peso de una fibra de corion anormal corresponde aproximadamente a 1,7 veces el peso de una fibra de corion normal. De este modo, si consideramos que la formación de los poros (tamaño y número) es el resultado de la interacción entre las fibras proteicas del corion y las microvellosidades del ovocito durante las etapas tempranas del desarrollo del huevo, al momento de producirse la polimerización de las fibras (Papadopoulou y col 1996), podemos sugerir que el aumento del grosor de las fibras polimerizadas traerá como consecuencia natural una reducción del número de poros y eventualmente también del tamaño de ellos. Los datos aquí reportados avalan esta idea ya que el número de poros descrito para el estrato interno de ovas con desarrollo anormal fue considerablemente menor que el número de poros observados en las muestras de corion con desarrollo normal y que lograron eclosionar.

En consecuencia, la presencia de fibras del corion más gruesas en las ovas que presentan desarrollo anormal (corion duro) se podría deber a cambios producidos en el peso molecular de las subunidades que forman la coriogenina tal como se ha reportado en este trabajo. La organización de las fibras del corion duro corresponde a la formación de polímeros de mayor tamaño con una estructura espacial y características químicas probablemente diferentes a la normal, características estas que hacen que la pared del corion duro se transforme en un sustrato más complejo y difícil de ser digerido por las enzimas de eclosión (coriolisinas). De esta manera el corion puede no ser degradado o, como ocurre en menor proporción, ser degradado sólo de manera parcial, produciéndose en ambos casos la muerte del alevín con ojo.

\section{RESUMEN}

El desarrollo temprano de los embriones de teleósteos ocurre al interior de una cubierta protectora denominada corion, la cual sufre un proceso de endurecimiento una vez ocurrida la fecundación. Cuando el embrión alcanza el estado de ova con ojo se produce la liberación del alevín por acción de la enzima de eclosión que degrada la pared del corion. En el último tiempo han ocurrido fracasos reproductivos importantes debido a que un gran porcentaje de alevines con saco, de algunas cohortes de Salmo salar, no logran romper el corion produciéndose con ello la muerte. En el mejor de los casos, un porcentaje menor de ovas logra romper el corion de manera parcial, eclosionando sólo una parte del cuerpo del embrión desde su saco vitelino, quedando el resto atrapado al interior del corion y destinado a morir. Estudios relacionados con la estructura del corion normal y el corion duro de Salmo salar indican que las fibras proteicas que forman el estrato interno del corion duro son más gruesas que las observadas en el corion normal, y por tanto parecen más difíciles de degradar. Dichos resultados conducen a pensar que una o más de las subunidades constituyentes de la coriogenina podrían estar alteradas en su estructura y por tanto forman un corion más grueso y difícil de digerir. Con el objetivo de corroborar esta afirmación propusimos realizar un estudio que permita caracterizar el patrón electroforético de las subunidades polipeptídicas que forman el corion duro así como de las que forman el corion normal. Nuestros resultados indican que las fibras proteicas del corion normal son más delgadas que las respectivas fibras observadas en el corion duro; del mismo modo, el patrón electroforético del corion normal corresponde a cuatro bandas de polipéptidos de peso molecular 107 kDa, 92 kDa, 38 kDa y 31 kDa respectivamente, mientras que en el caso del corion duro las bandas electroforéticas migraron a los $179 \mathrm{Kda}, 157 \mathrm{Kda}, 55 \mathrm{Kda}$ y $54 \mathrm{Kda}$. En consecuencia, las fibras más gruesas observadas en las ovas con corion duro son el resultado de cambios producidos en el peso molecular de las subunidades que forman la coriogenina. Las fibras del corion duro corresponden a la agregación de polímeros de mayor tamaño con una estructura espacial y características químicas diferentes a las fibras que forman el corion normal. Dichas características harían que la pared del corion duro corresponda a un sustrato diferente, y en apariencia más complejo y difícil de ser digerido por las enzimas de eclosión (coriolisinas). De esta manera el corion no es degradado o es degradado de manera parcial como ocurre en algunos casos produciéndose en ambos casos la muerte del alevín con ojo.

\section{REFERENCIAS}

Brivio MF, R Bassi, F Cotelli. 1991. Identification and characterization of the major components of the Oncorhynchus mykiss Egg Chorion. Mol Reprod Develop 28, 85-93.

Celius T, BT Walther. 1998. Oogenesis in Atlantic salmon (Salmo salar L.) occurs by zonagenesis preceding vitellogenesis in vivo and in vitro. J Endocr 158, 259-266.

Darie CC, ML Biniossek, MA Gawinowicz, Y Milgrom, JO Thumafart, L Jovine, ES Litscher, PM Wassarman. 2005. Mass spectrometric evidence that proteolytic processing of Rainbow trout egg vitelline envelope proteins takes place on the egg. J Biol Chem 280, 3758537598.

Fausto AM, M Carcupino, G Scapigliati, AR Taddei, M Mazzini. 1994. Fine structure of the chorion and mycropyle of the sea bass egg Dicentrarchus labrax (Teleostea, Percichthydae). Int J Zoology 61, 129-133.

Iconomidou VA, DG Chryssikos, V Gionis, MA Pavlidis, SJ Hamodrakas. 2000. Secondary structure of chorion proteins of the teleostean fish 
Dentex dentex by ATR FT-IR and FT-Raman spectroscopy. J Struc Biol 132, 112-122.

Iuchi I, K Masuda, K Yamagami. 1991. Change in component proteins of the egg envelope (chorion) of Rainbow trout during hardening. Develop Growth Differ 33, 86-92.

Iuchi I, CR Ha, H Sugiyama, K Nomura. 1996. Analysis of chorion hardening of eggs of Rainbow trout, Oncorhynchus mykiss. Develop Growth Differ 38, 299-306.

Jaramillo R, O Goicoechea, O Garrido, E Molinari. 2009. Salmo salar: Morfología ultraestructural de la pared del corion en ovas normales y con problemas de eclosión. Arch Med Vet 41, 67-71.

Kusa M. 1949. Hardening of the chorion of Salmon egg. Cytol 15, 145-148.

Laemmli UK. 1970. Cleave of structural protein during the assembly of the head of bacteriophage T4. Nature 227, 680-685.

Lyons CE, Payette KL, Price JL, Huang RCC. 1993 Expression and structural analysis of a teleost homolog of mammalian zona pellucida gene. J Biol Chem 268, 21351-21358.

Masuda K, I luchi, K Yamagami. 1991. Analysis of hardening of the egg envelope (Chorion) of the fish, Oryzias latipes. Develop Growth \& Differ 33, 75-83.

McMillan, DB. 2007. Fish histology, female reproductive systems. Springer-Verlag Publishers, The Netherlands.

Mekkawy AA, GM Osman. 2006. Ultrastructural Studies of the morphological variations of the egg surface and envelopes of the African catfish Clarias gariepinus (Burchell, 1822) before and after fertilization, with a discussion of the fertilization mechanism. Scientia Marina 70S2, 23-40.
Murata K, H Sugiyama, S Yasumasu, I Iuchi, I Yasumasu, K Yamagami.1997. Cloning of cDNA and estrogen-induced hepatic gene expression for choriogenin $\mathrm{H}$, a precursor of the fish egg envelope (chorion). Proc Natl Acad Sci USA 94, 2050-2055.

Papadopoulou P, VK Galanopoulos, SJ Hamodrakas. 1996. Molecular and supramolecular architecture of the Salmo gairneri proteinaceous eggshell during development. J Structural Biol 116, 399-412.

Riehl R. 1991. Structure of oocytes and egg envelopes in oviparous teleostets, an overview. Acta Biol Benrodis 3, 27-65.

Riehl R, H Greven. 1993. Fine structure of egg envelopes in some viviparous goodeid fishes, with comments on the relation of envelope thinness to vivipary. Can J Zool 71, 91-97.

Sugiyama H, K Murata, I Iuchi, K Nomura, K Yamagami. 1999. Formation of mature egg envelope subunit proteins from their precursors (Choriogenins) in the fish, Oryzias latipes: loss of partial C-terminal sequences of the choriogenins. J Biochem 125, 469-475.

Schmehl MK, EF Graham. 1987. Comparative ultrastructure of the zona radiata from eggs of six species of Salmonids. Cell Tissue Res 25, 513-519.

Thiaw OT, X Mattei. 1991. Morphogenesis of the secondary envelope of the oocyte in a teleostean fish of the family Cyprinodontidae Aphyosemion splendopleure. J Submicroscopic Cytol and Pathol 23, 419-426.

Yamagami K. 1981. Mechanism of hatching in fish: secretion of hatching enzyme and enzymatic choriolysis. Am Zool 21, 459-471. 